[0212-7199 (2006) 23: 7; pp 331-334] ANALES DE MEDICINA INTERNA Copyright (C) 2006 ARAN EDICIONES, S.L.

AN. MED INTERNA (Madrid) Vol. 23, N. ${ }^{\circ}$, pp. 331-334, 2006

\title{
Encefalitis límbica paraneoplásica y carcinoma epidermoide del seno piriforme
}

\author{
M. A. SOBAS, M. A. GALIANO LEIS ${ }^{1}$, R. DE LA FUENTE CID, \\ I. PEREIRO ZABALA
}

Servicios de Medicina Interna, ${ }^{1}$ Medicina Familiar y ${ }^{2}$ Radiología. Hospital de Conxo. Complejo Hospitalario Universitario. Santiago de Compostela (CHUS)

\author{
PARANEOPLASTIC LIMBIC ENCEPHALITIS AND EPIDERMOID \\ CARCINOMA OF THE PYRIFORM SINUS
}

\section{RESUMEN}

La encefalitis límbica paraneoplásica es un síndrome que se caracteriza clínicamente por alteraciones de comportamiento, trastornos de memoria reciente y crisis epilépticas.

Presentamos el caso clínico de un varón de 62 años, ex-fumador, que ingresa en UCI por un cuadro de crisis convulsivas, presentando anteriormente cambios en el carácter. Los estudios practicados resultaron negativos a excepción de LCR con hiperproteinorraquia y RNM que mostraba lesiones en el lóbulo temporal. Una vez descartadas otras posibles etiologías, iniciamos despistaje de neoplasia oculta.

No se evidenció tumor en las pruebas de imagen habituales. Los anticuerpos anti-Hu resultaron negativos. Se realizó tomografía de emisión de positrones (TEP) de cuerpo entero que reveló un foco de hipercaptación a nivel faringolaríngeo. La biopsia fue diagnóstica de carcinoma epidermoide del seno piriforme.

En nuestro conocimiento es el primer caso de ELP asociada a carcinoma epidermoide del seno piriforme.

PALABRAS CLAVE: Encefalitis límbica paraneoplásica. Anticuerpos antineuronales. Carcinoma epidermoide del seno piriforme.

\begin{abstract}
Paraneoplastic limbic encephalitis is a syndrome characterised by behaviour changes, short-term memory loss and seizures.

We report on a case of a 62-year-old man, ex-smoker who was admitted to the Intensive Care Unit with seizures, and who had previously experienced behaviour changes. Tests revealed nothing notable, except for the CSF examination which revealed elevated protein and MRI findings indicating temporal lobe abnormalities. Once other diagnoses had been ruled out, neoplasm screening was initiated.

Conventional imaging failed to identify the tumour. Antineuronal anti-Hu antibodies were negative. Finally, fluorodeoxyglucose (FDG) whole body -PET imaging was carried out revealing a pathologically increased glucose metabolism at the pharynx-larynx level. The biopsy showed an epidermoid carcinoma of the pyriform sinus.

To the best of our knowledge, this is the first reported case of an epidermoid carcinoma of the pyriform sinus associated with paraneoplastic limbic encephalitis.
\end{abstract}

KEY WORDS: Paraneoplastic limbic encephalitis. Antineuronal antibodies. Epidermoid carcinoma of the pyriform sinus.

Sobas MA, Galiano Leis MA, de la Fuente Cid R, Pereiro Zabala I. Encefalitis límbica paraneoplásica y carcinoma epidermoide del seno piriforme. An Med Interna (Madrid) 2006; 23: 331-334.

\section{INTRODUCCIÓN}

La encefalitis límbica paraneoplásica (ELP) forma parte de los síndromes paraneoplásicos del sistema nervioso (Tabla I). Su máxima incidencia es en la sexta década de la vida (1). Afecta por igual a hombres y a mujeres y las neoplásias más frecuentemente asociadas son el carcinoma pulmonar de células pequeñas, los seminomas y los linfomas hodgkinianos $(2,3)$; si bien se han descrito asociados a múltiples tipos histológicos y localizaciones. En más de dos tercios de los casos los síntomas neurológicos preceden a la identificación de la neoplasia primitiva $(2,4)$.
El diagnóstico de ELP exige: a) cuadro clínico compatible: cambios de personalidad y comportamiento, trastornos de memoria (fallos en memoria reciente y de fijación, amnesia y tendencia a fabulaciones, ocasionalmente con criterios de demencia) y convulsiones; b) periodo inferior a 4 años entre la presentación del cuadro de ELP y el diagnóstico de la neoplasia; c) exclusión de otras etiologías (metástasis, infección oportunista, efectos tóxicos de quimioterapia) que justifiquen el cuadro encefálico; y d) al menos uno de los siguientes: LCR alterado (pleocitosis, hiperproteinorraquia, citología negativa para malignidad), lesión en la RMN del lóbulo temporal y EEG con actividad epileptiforme del lóbulo temporal (2).

Trabajo aceptado: 25 de enero de 2007 
La búsqueda de Ac antineuronales en sangre y/o LCR es positiva en $60 \%$ de los casos $(2,5)$, aunque su negatividad no excluye el diagnóstico. Los más frecuentes y conocidos son los Ac anti-Hu, si bien en la tabla II aparecen reflejados los distintos Ac identificados en casos de ELP. Por otra parte los Ac parecen tener únicamente papel en la ayuda al diagnóstico, desconociéndose su auténtico valor patogénico y pronóstico; presentando además las siguientes limitaciones: a) su presencia en sangre aparece sólo en el $60 \%$ de los casos; b) pueden aparecer en encefalitis lìmbicas no-neoplásicas; c) las asociaciones síndrome paraneoplásico-Ac-tumor no son fijas; y d) al ser un estudio relativamente nuevo resulta caro y de accesibilidad limitada (3).

El tratamiento de la ELP conlleva tres aspectos: control de los síntomas neurológicos, tratamiento "patogénico" (inmunoglobulinas y esteroides) y búsqueda de la neoplasia de base para su posible tratamiento $(2,3)$.

El pronóstico dependerá fundamentalmente del diagnóstico y tratamiento precoz de la neoplasia de base $(2,3)$.

\section{TABLA I}

\section{SÍNDROMES NEUROLÓGICOS PARANEOPLÁSICOS}

Sistema implicado

Sistema nervioso central: $\quad$ Encefalomielitis multifocal

Degeneración cerebelosa

Encefalitis límbica

Opsoclonus-mioclonus

Síndrome extrapiramidal

Encefalitis de tronco cerebral

Mielopatía necrotizante

Enfermedad de neurona motora

Stiff person syndrom

Neuritis óptica

Degeneración retiniana

Sistema nervioso periférico: Neuropatía sensorial

Vasculitis nerviosa

Polineuropatía sensomotora

Neuropatía motora

Neuromiotonía

Insuficiencia de sistema nervioso autónomo

Síndrome de Eaton-Lambert

Miopatía inflamatoria

Miopatía necrotizante

\section{CASO APORTADO}

Un varón de 62 años, ex-fumador sin otros antecedentes de interés, ingresa en la UCI de nuestro centro por estatus convulsivo.

\section{TABLA II}

\section{AUTOANTICUERPOS RELACIONADOS CON ELP}

Linfoma de Hodgkin

Carcinoma pulmonar oat-cell

Tumor testicular, tumor mamario

Timoma
Anti-Tr, anti-mCluR1

Anti-Hu, anti-CV2, PCA-2, ANNA-3, antianfifisina, anti-VGKC, anti-Zic4

Anti-Ma2

Anti-VGKC, anti-CV2
Según su familia, en las últimas semanas se mostraba irritable y con comportamiento infantil, además de haberse quejado en las últimos días de pesadez y adormecimiento en miembros derechos. Se controlan las crisis con fenitoína i.v. No había hallazgos destacables en las pruebas (analítica, ECG, TC cerebral) realizadas de urgencia, a excepción de atelectasia basal derecha en la Rx de tórax. Se practicó una punción lumbar que mostró LCR acelular pero con hiperproteinorraquia ( $72 \mathrm{mg} / \mathrm{dl}$ de proteínas) y EEG con actividad irritativa temporal izquierda. Un estudio de RNM cerebral evidenció lesión de hiperseñal sobre lóbulo temporal izquierdo (secuencias FLAIR y difusión) (Fig. 1), que no se modificó tras la administración de contraste paramagnético, ni presentó focos de hemorragia en la evolución.
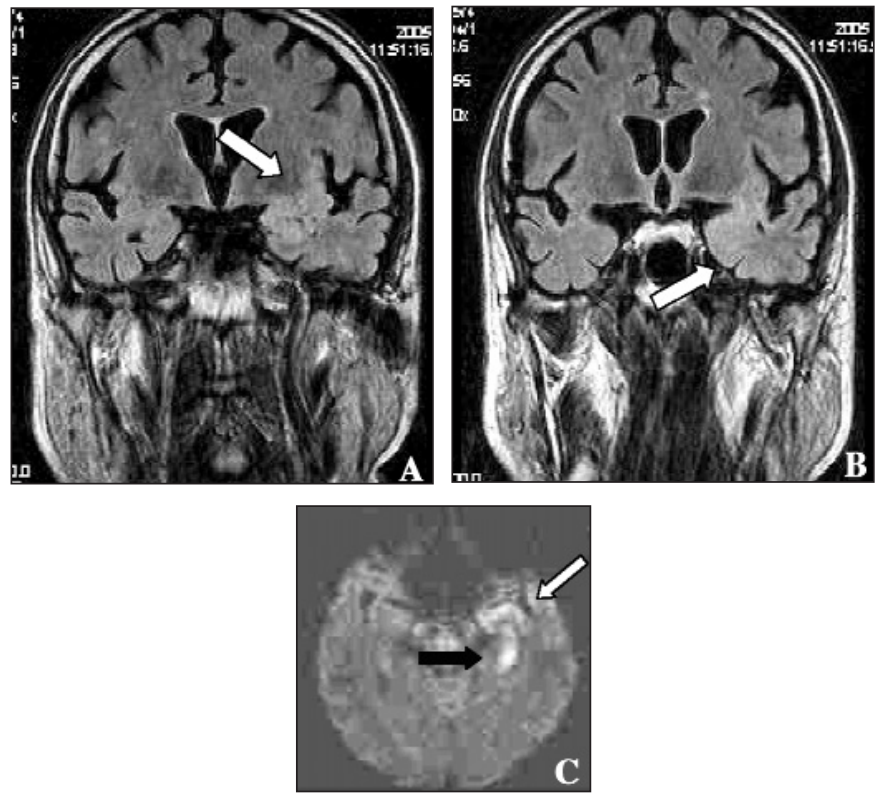

Fig. 1. Estudio de RM cerebral; Coronal FLAIR (Imágenes $a-b$ ), demuestran una zona de hiperintensidad en región hipocampal e insular izquierdas, con engrosamiento del hipocampo con respecto al contralateral, que brillan en la secuencias de difusión (c).

Se añadió al tratamiento con fenitoína, aciclovir (a la espera de PCR frente a herpes simple) y antibioterapia (neumonía) con Tazocel y Teicoplanina. No volvió a presentar convulsiones y se mantuvo afebril, siendo trasladado a planta de Medicina Interna. Al ingreso no hay hallazgos destacables en la exploración física y en la neurológica se muestra consciente, con disfasia nominal, ánimo inapropiado, déficit de atención y tendencia a fabular y leve hemiparesia derecha. En los días siguientes mejoró (recupero la paresia y el lenguaje se normalizó) aunque persistió moria y síndrome de Korsakoff. Se completó tratamiento con Aciclovir (al sexto día se recibió PCR negativa para VHS) y antibioterapia.

Los estudios analíticos fueron irrelevantes, a excepción de leve elevación de CEA (3,9 ng/ml). Los anticuerpos anti-Hu, antitiroides, serologías (lúes, VIH, virus neurotropos) fueron negativas. Se inició despistaje de neoplasia oculta empezando por TAC toracoabdominal (normal salvo por atelectasia/neumonía LDI), broncoscopio con lavado broncoalveolar (negativa), endoscopia digestiva alta y baja, tránsito intestinal, valoración urológica, gammografía ósea y biopsia de médula ósea. Dada la normalidad de dichos estudios, y con el diagnóstico de ELP se solicitó estudio de TEP de cuerpo entero, que evidenció la presencia de una hipercaptación de fluoroglucosa a nivel faringolaríngeo, así como pequeñas adenopatías satélites. Se 


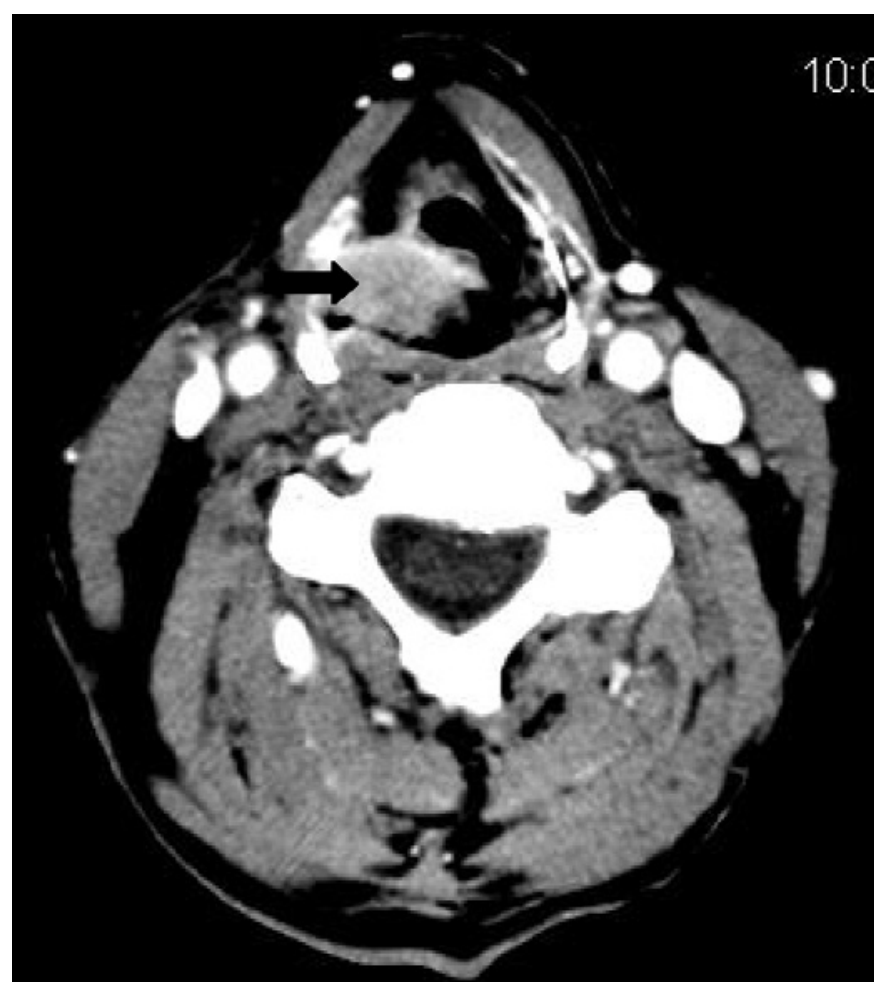

Fig. 2. EI TAC con contraste intravenoso de la región faríngea demuestra una masa hipercaptante en seno piriforme derecho, que impronta sobre la vía aérea (flecha).

confirmó el hallazgo de TEP con el TAC del cuello y estudio anatomo-patológico de la lesión que fue diagnóstica de carcinoma epidermoide del seno piriforme.

\section{DISCUSIÓN}

Nuestro paciente presentaba al ingreso un cuadro clínico que planteaba diversas posibilidades etiológicas, incluyendo encefalitis infecciosas (herpes simple, herpes zóster, VIH y lúes), encefalitis autoinmunes (encefalitis de Hashimoto) y encefalitis límbica paraneoplásica. Una vez descartadas las dos primeras posibilidades y comprobado el cumplimento de los criterios diagnósticos, se llega al diagnóstico de ELP $(1,2)$.

La ELP pertenece al grupo de síndromes paraneoplásicos neurológicos, que se dividen según la afectación del sistema nervioso central o periférico (Tabla I) $(3,6)$. La primera descripción de la encefalitis límbica paraneoplásica aparece en 1960, cuando Brierly presenta su asociación con el carcinoma pulmonar de células pequeñas. Desde entonces se han descrito otros casos asociados a diferentes neoplasias, principalmente a seminoma, linfoma no Hodgkin, timoma y cáncer de mama $(2,3)$.

La patogenia más probable es la autoinmune. Las células tumorales presentan sus antígenos (que se parecen a los antígenos neuronales) a los macrófagos que al procesarlos los presentan a su vez a los linfocitos CD4 helper y CD8 citotóxicos. Los linfocitos activados atraviesan la barrera hematoencefáli- ca y por un lado los CD4 inducen la producción de autoanticuerpos contra las células neuronales y por otro los CD8 inician la acción citotóxica neuronal directa (7).

En estudios in vitro con cultivos neuronales de pacientes se observa título elevado de autoanticuerpos anti-Hu y antiYo sin apreciarse daño neuronal directo. Además en estudios de animales inmunizados con antígenos Hu o Yo se desarrolló un título alto de autoanticuerpos sin evidenciarse signos clínicos ni patológicos de enfermedad. Todo ello parece llevar a la conclusión de que los autoanticuerpos no están implicados en el daño neuronal, sino que actuarían como los marcadores del proceso autoinmune (3).

Se ha observado que algunos de los anticuerpos antineuronales presentan mayor asociación con determinados síndromes paraneoplásicos y procesos tumorales. En caso de encefalitis límbica los anticuerpos más relacionados son los anti-Hu, anti-Ta(Ma2) y otros (Tabla II) (3). Los autoanticuerpos pueden generar en ocasiones confusión. Ya hemos comentado que su presencia en sangre se descubre solamente en el $60 \%$ de los casos de ELP y que se han descrito casos de encefalitis límbica no paraneoplásica con presencia de dichos anticuerpos. Además las asociaciones de síndrome-Ac-neoplasia no son fijas, existiendo por ejemplo casos del mismo autoanticuerpo en diferentes neoplasias y de la misma neoplasia con diferentes autoanticuerpos. Por otro lado últimamente se están descubriendo nuevos anticuerpos antineuronales por lo que no es posible solicitar la detección de todos ellos por limitación económica y accesibilidad del estudio.

Concluyendo, el estudio de anticuerpos en nuestro paciente no nos acercó al diagnóstico final. Dado que el tratamiento del proceso precisa de la identificación tumoral decidimos proseguir con el estudio de detección del proceso de base. La existencia de frecuente asociación de ELP con carcinoma pulmonar oat-cell nos llevó a la realización de Rx de tórax, TC torácico y broncoscopía cuyos resultados fueron negativos para malignidad. Igualmente resultó infructuosa la localización de neoplasia oculta del tubo digestivo, seminoma y linfoma. Por ello se realizó tomografía de emisión de positrones (TEP) que permitió localizar una lesión sospechosa a nivel cervical. Sin embargo teniendo en cuanta que TEP es una prueba con elevada sensibilidad (en torno al 90\%) y con poca especificidad (menor del 30\%) es necesario confirmar el hallazgo con una prueba convencional; en nuestro caso TC de cuello y estudio anatomo-patológico (5).

Actualmente no existen protocolos de actuación en caso de ELP. Parece sin embargo que lo más efectivo es el tratamiento del tumor de base. Teniendo en cuenta que el síndrome paraneoplásico suele anteceder (media de tres meses y medio) (2) al diagnóstico de la neoplasia, actuando sin demora podemos mejorar el pronóstico oncológico del paciente. Por ello es esencial la búsqueda de la neoplasia oculta.

Otra posibilidad terapéutica es el tratamiento inmunomodulador que no debe usarse aisladamente si no asociado a lo anterior $(2,3,8)$.

No hemos hallado en la bibliografía revisada ningún otro caso de síndrome paraneoplásico asociado a carcinoma epidermoide de seno piriforme, por lo que es el primer caso del que tenemos conocimiento. 


\section{Bibliografía}

1. Bien CG, Schulze-Bonhage A, Deckert M, et al. Limbic encephalitis not associated with neoplasm as a cause of temporal lobe epilepsy. Neurology 2000; 55: 1823-1828

2. Gultekin SH, Rosenfeld MR, Voltz R, et al. Paraneoplastic limbic encephalitis: neurological symptoms, immunological findings and tumor association in 50 patients. Brain 2000; 123: 1481-1494.

3. Dropcho EJ. Update on paraneoplastic syndromes. Current Opinion in Neurology 2005; 18: 331-336.

4. Gil Ortega M, Hernandéz Pardo E, Gil Ortega I, et al. Encefalitis límbica paraneoplásica y cáncer de pulmón. An Med Interna (Madrid) 2004; 21 : 129-130.

5. Younes-Mhenni S, Janier MF, Cinotti F, et al. FDG-PET improves tumour detection in pacientes with paraneoplastic neurological syndromes. Brain 2004; 127: 2331-2338.

6. Graus F, Delattre JY, Antoine JC, et al. Recommended diagnostic criteria for paraneoplastic neurological syndromes. J Neurol Neurosurg Psychiatry 2004; 74: 1135-1140.

7. Raymond V, Paraneoplastic neurological syndromes. Current Opinion in Neurology 2005; 123: 1461-1494.

8. Sunil K. Munshi, Bhomraj Thanvi, Su Kiun Chin, et al. Paraneoplastic limbic encephalitis-case report and review of literature. Age and Ageing 2005; 34: 190-193.

9. Iseri P, Akansel G, Budak F. Magnetic Resonance Imaginig findings in patient with bilateral limbic encephalitis. Arch Neurol 2005; 62: 1014-1015. 